\title{
BMJ Open Satisfaction with maternity care among recent migrants: an interview questionnaire-based study
}

\author{
Sukhjeet Bains (1) , ${ }^{1,2}$ Johanne Sundby, ${ }^{2}$ Benedikte V. Lindskog, ${ }^{3}$ Siri Vangen, ${ }^{1,4}$ \\ Lien M. Diep, ${ }^{5}$ Katrine M. Owe, ${ }^{6}$ Ingvil K. Sorbye ${ }^{1}$
}

To cite: Bains S, Sundby J, Lindskog BV, et al. Satisfaction with maternity care among recent migrants: an interview questionnairebased study. BMJ Open 2021;11:e048077. doi:10.1136/ bmjopen-2020-048077

- Prepublication history and additional supplemental material for this paper are available online. To view these files, please visit the journal online (http://dx.doi.org/10.1136/ bmjopen-2020-048077).

Received 16 December 2020 Accepted 06 July 2021

Check for updates

(C) Author(s) (or their employer(s)) 2021. Re-use permitted under CC BY-NC. No commercial re-use. See rights and permissions. Published by BMJ.

For numbered affiliations see end of article.

Correspondence to

Dr Sukhjeet Bains;

sukhjeetkb@gmail.com

\section{ABSTRACT}

Objective To examine factors associated with recently migrated women's satisfaction with maternity care in urban 0slo, Norway.

Design An interview-based cross-sectional study, using a modified version of Migrant Friendly Maternity Care Questionnaire.

Setting Face-to-face interview after birth in two maternity wards in urban Oslo, Norway, from January 2019 to February 2020.

Participants International migrant women, $\leq 5$ years length of residency in Norway, giving birth in urban 0slo, excluding women born in high-income countries.

Primary outcome Dissatisfaction of care during pregnancy and birth, measured using a Likert scale, grouped into satisfied and dissatisfied, in relation to socio-demographic/clinical characteristics and healthcare experiences.

Secondary outcome Negative healthcare experiences and their association with reason for migration.

Results A total of 401 women answered the questionnaire (87.6\% response rate). Overall satisfaction with maternal healthcare was high. However, having a Norwegian partner, higher education and high Norwegian language comprehension were associated with greater odds of being dissatisfied with care. One-third of all women did not understand the information provided by the healthcare personnel during maternity care. More women with refugee background felt treated differently because of factors such as religion, language and skin colour, than women who migrated due to family reunification. Conclusions Although the overall satisfaction was high, for certain healthcare experiences such as understanding information, we found more negative responses. The negative healthcare experiences and factors associated with satisfaction identified in this study have implications for health system planning, education of healthcare personnel and strategies for quality improvement.

\section{INTRODUCTION}

With rising proportions of births to migrant women across Europe, there is a growing need for more knowledge about the reproductive health of migrants. ${ }^{1}$ Many migrants are of childbearing age and some have their first contact with the healthcare system in the new country when seeking maternity care. Higher

\section{Strengths and limitations of this study}

Face-to-face interviews with interpreter enabled all women to participate, regardless of language proficiency and literacy.

- The use of the questionnaire tool, Migrant Friendly Maternity Care Questionnaire, enables comparability across countries.

- Timing of questionnaire shortly after birth may introduce a bias as birth outcome might influence perception of maternity care.

- As the interviews were conducted in the postnatal ward, some women may have been reluctant to share negative experiences about inpatient care.

maternal mortality and morbidity have been found among migrants compared with the host population in a number of European countries. ${ }^{2-5}$ Several reasons for the elevated risk of adverse obstetric outcomes exist, such as substandard care and varying risk profiles for subgroups of migrants. ${ }^{2}$ Other reasons include late initiation of antenatal care and fewer antenatal visits among migrants, which in turn can be caused by low health literacy. ${ }^{6-10}$

Satisfaction with care is considered a key predictor of utilisation of healthcare services, which in turn can be a modifiable risk factor for adverse outcomes. ${ }^{211-14}$ The WHO recommends measuring maternal satisfaction of care to improve quality of healthcare.$^{15}$ Sitzia and Wood define 'satisfaction' as both a measure of the care received and a reflection of the patients as it consists of the patient's personal preferences, the expectations and the actual care received. ${ }^{16}$ Literature suggests that different experiences of care, for instance, support from healthcare personnel and involvement in decision-making, are the most important predictors of maternal satisfaction. ${ }^{17-19}$ Reproductive history, age and socioeconomic status are other known factors influencing perceived maternal satisfaction. ${ }^{20}$ 
Socioeconomic status is a predictor of inadequate antenatal care among migrants and as such, women born in low-income or middle-income countries are at a higher risk. ${ }^{10}$ Recently arrived pregnant women are particularly vulnerable. In addition to their migration experience, that for many implies a loss of social network and socioeconomic disadvantage, they are more likely to have less majority language proficiency and health system literacy. ${ }^{21}$ Discrepancies exist within subgroups of migrants, where refugees and asylum-seekers seem to have higher risk for adverse outcomes, in contrast to people who migrate because of work and education, who tend to be wealthier and have better health. ${ }^{22}$

Disparities in maternal health outcomes and suboptimal quality of maternity care for migrants are also reported from Norway. ${ }^{42324}$ In order to improve quality of care, it is important to gain more knowledge about determinants of migrated women's satisfaction with maternity care. A literature gap exists regarding these determinants, especially for the most recently arrived groups of migrants. The main objective of this study was, therefore, to examine factors associated with recently migrated women's satisfaction with maternity care. The secondary objective was to examine the association between healthcare experiences and subgroups of migrants by reason for migration. We examined these factors among women in urban Oslo, the region with the highest proportions of migrants in Norway, in a setting of free universal access to maternity care.

\section{METHODS}

\section{Study design and setting}

This interview questionnaire-based study is part of the MiPreg project and was conducted between January 2019 and January 2020. The Mipreg project is a multidisciplinary, mixed method project that seeks to identify factors that explain disparities in pregnancy outcomes among recently migrated women in Norway. Norway has universal health coverage and essential maternity care is free of charge for all legal citizens. Persons without legal residence have right to healthcare but must pay for it. ${ }^{25}$ Pregnant women can choose between follow-up by a general practitioner or a midwife at a maternity and child healthcare centre. ${ }^{26}$ The standard antenatal package includes 8 consultations, including 1 routine ultrasound examination around weeks 17-19. Almost all births in Norway occur in public hospitals. After discharge from hospital, the maternity and child healthcare centre provide the postnatal follow-up. ${ }^{27}$

\section{Study participants}

We included internationally migrated, recently pregnant women with a length of stay in Norway $\leq 5$ years, giving birth in urban Oslo. We excluded migrants born in high-income countries, according to the Global Burden of Disease framework. Eligible women were recruited from the two public hospitals that serve urban Oslo with

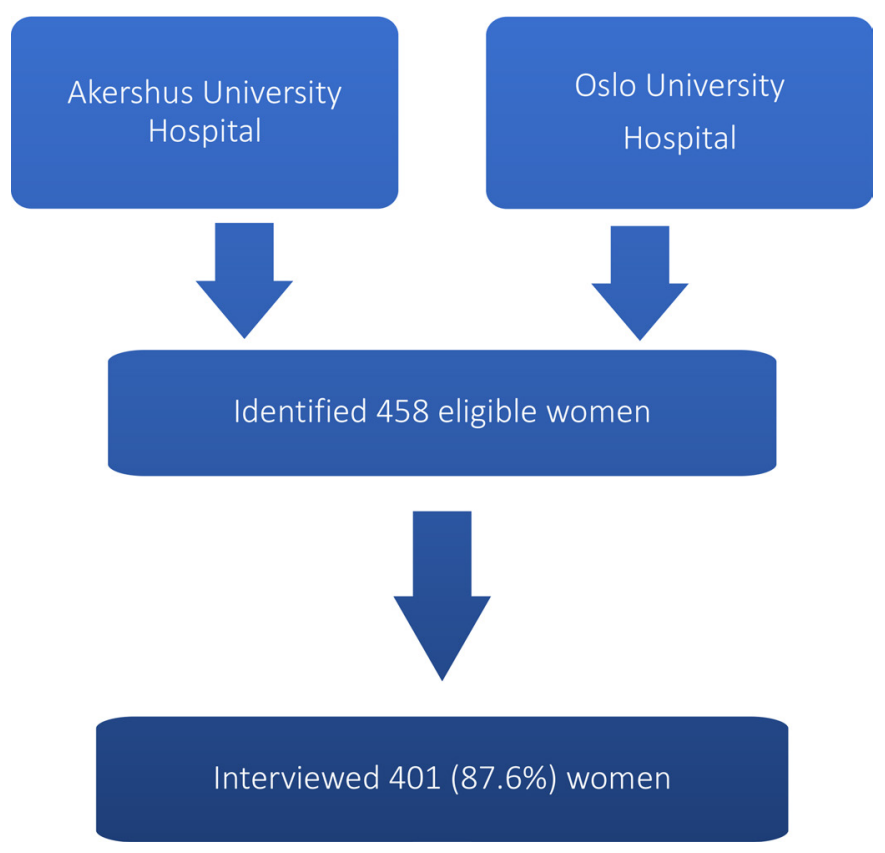

Figure 1 Flowchart inclusion.

approximately 14800 births annually: Oslo University Hospital and Akershus University Hospital.

\section{Questionnaire}

We applied a quantitative questionnaire, using a modified version of the Migrant Friendly Maternity Care Questionnaire (MFMCQ) (online supplemental file 1). MFMCQ is a structured questionnaire on maternity care developed to be used in migrant populations. ${ }^{28}$ It includes information on maternal socio-demographic, migration and obstetric characteristics as well as satisfaction of care and other healthcare experiences during pregnancy and birth. The original questionnaire was adapted to the health system setting of Norway and modified after inputs from pilot testing. An interview guidebook was produced and training workshops for all the research personnel, one medical doctor and three midwives, were conducted. The interviewers met regularly to discuss challenges and experiences.

\section{Data collection}

The maternal healthcare in Norway is fragmented, meaning the healthcare before, during and after birth is administered by independent institutions. Therefore, to elicit responses from hard-to-reach groups that we would otherwise miss, the eligible women were recruited either on admission for delivery or at the postnatal ward (figure 1). The research personnel informed women about the study and a written consent was obtained. Thereafter, they conducted the interviews face to face in the women's own language of choice after birth, using an interpreter when needed. In addition, to aid the women in understanding the structure of the question and the answer options, written translations of the questionnaire were provided in nine languages: Arabic, Dari, English, French, Norwegian, Somali, Sorani, Tigrinya and Urdu. 
The questionnaire was forward-translated by a certified translating company with extensive knowledge about medico-technical-related and pregnancy-related terms. The back-translating was performed blinded. We further systematically compared the back-translated questionnaire with the source language version, noting all discrepancies and adjusted accordingly.

\section{Outcome variable}

Satisfaction of care was assessed using the question, 'Overall, were you satisfied with the care you received?', combined for the two time periods: care during pregnancy and care during birth, with the response options 'always', 'sometimes', 'rarely' and 'never'. As the distribution of satisfaction data was strongly skewed, we categorised the data to be binary, with 'satisfied' (including 'always satisfied') and 'dissatisfied' (combining 'sometimes', 'rarely' and 'never'). There were no missing values.

\section{Explanatory variables}

Country of birth was grouped into super-regions following the Global Burden of Disease classifications, based on epidemiological similarity and geographic closeness: Latin America and Caribbean; Sub-Saharan Africa; North Africa and Middle East; South East Asia, East Asia and Oceania; South Asia; and Central Europe, Eastern Europe and Central Asia. ${ }^{29}$ As to reason(s) for migration, we used the national classification based on the legal grounds for immigration. We grouped women into one out of three categories: refugee, work/education and family reunification. Maternal education was classified into three groups: no completed education, primary and secondary school, or university. Economic status was measured by asking the women if she had experienced difficulties making ends meet and paying monthly expenses, with responses 'yes often', 'yes occasionally' or 'no never'. Having a Norwegian partner implied that the partner was born in Norway, regardless of ethnicity. Healthcare experiences were examined by asking the women about 11 specific healthcare experiences, grouped binary as positive or negative experiences.

\section{Statistical analysis}

A sample size of approximately 360 women was required to detect a difference of $14 \%$ between 2 groups with and without full satisfaction, assuming that the proportion of fully satisfied women was $73 \%$ as the reference/control group. ${ }^{30}$ A two-sided significance level of 0.05 and $80 \%$ power were used. We decided to include approximately 400 women to take potential missing values into account. The calculation of sample size was performed with Stata/ SE V.16.1. Descriptive statistics as mean with SD and frequencies with percentages were calculated for categorical and continuous variables. The difference between two independent proportions of 'always satisfied' and 'not always satisfied' was tested by using a $\chi^{2}$ test. Association between socio-demographic and clinical variables with primary and secondary outcomes was examined by using univariable and multivariable logistic regressions. The association was expressed as the OR with $95 \%$ CI and the Hosmer-Lemeshow test was used to inspect global goodness of fit for the logistic regression models. Two-sided $p$ values were reported, and the significance level was set at $0.05 . \chi^{2}$ test was used for the healthcare experiences among different migrant groups and if a significant association was found, we conducted a pairwise z-test post-hoc analysis with Bonferroni correction. The analyses were performed with IBM SPSS V.25.

\section{Patient and public involvement}

The MiPreg project has, from the design phase throughout the implementation phase, involved user representatives from non-governmental organisations and relevant migrant communities within the greater Oslo area. The user representatives gave feedback on readability, validity and cultural sensitivity of the questionnaire before data collection. After data collection, preliminary findings were presented, and interpretations were discussed with user representatives.

\section{RESULTS \\ Socio-demographic and clinical characteristics of study participants}

In total, 401 women completed the interview, 160 women from Akershus University Hospital and 241 women from Oslo University Hospital, giving an $87.6 \%$ response rate (figure 1). The 57 non-participating women did not differ from the participants in terms of age, length of residence or region of birth. The main reason for not participating was 'being tired' and 'not having the time'. The mean completion time for the interview was $44 \mathrm{~min}$ (SD: 13 $\mathrm{min}$ ). All boroughs in the city of Oslo were represented, including surrounding counties which constitute the 'greater Oslo region'. The median age for primiparous women was 29 years and for multiparous women was 31 years. In total, the women originated from 66 different countries. Twenty-eight per cent of the women had lived in Norway for up to 1 year and 11 months, $37 \%$ for 2 years up to 3 years and 11 months and $35 \%$ for 4 years up to 5 years. The majority of women were primiparous. Almost one in four women had induction of labour $(24.2 \%)$ and almost every fifth women had a caesarean section $(18.0 \%)$. No difference in dissatisfaction was found for women receiving maternity care from a general practitioner $(28.7 \%)$, a midwife $(29.0 \%)$ or an obstetrician (28.1\%) (table 1).

\section{Socio-demographic and clinical factors associated with women's dissatisfaction}

Women with a non-Norwegian partner had decreased odds of being dissatisfied with overall care, compared with women with a Norwegian partner (adjusted OR: $0.38,95 \%$ CI 0.18 to 0.82 , figure 2 ). Having completed primary and secondary education reduced the odds of being dissatisfied compared with those with higher 
Table 1 Socio-demographic and clinical characteristics of all study participants and for overall dissatisfaction, $\mathrm{n}(\%)$ or mean (SD)

\begin{tabular}{llc}
\hline $\begin{array}{l}\text { Socio-demographic and } \\
\text { clinical characteristics }\end{array}$ & All (n=401) & $\begin{array}{l}\text { Dissatisfied* } \\
(\mathbf{n = 1 1 3})\end{array}$ \\
\hline $\begin{array}{l}\text { Socio-demographic } \\
\text { characteristics }\end{array}$ & $29.8(4.7)$ & $29.8(4.7)$ \\
\hline $\begin{array}{l}\text { Age (years), mean (SD) } \\
\text { Mother's region of birth } \\
\text { (GBD), n (\%) }\end{array}$ & $37(32.7)$ \\
$\begin{array}{l}\text { Central Europe, Eastern } \\
\text { Europe and Central Asia }\end{array}$ & $132(32.9)$ & $7(6.2)$ \\
$\begin{array}{l}\text { Latin America and } \\
\text { Caribbean }\end{array}$ & $13(3.2)$ & $24(21.2)$ \\
\hline $\begin{array}{l}\text { North Africa and Middle } \\
\text { East }\end{array}$ & $76(19.0)$ & $21(18.6)$ \\
\hline $\begin{array}{l}\text { South Asia } \\
\text { Southeast Asia, East }\end{array}$ & $37(9.2)$ & $8(7.1)$ \\
Asia and Oceania & & $16(14.2)$ \\
\hline $\begin{array}{l}\text { Sub-Saharan Africa } \\
\text { Patner's region of birth }\end{array}$ & $62(15.5)$ &
\end{tabular}

Partner's region of birth

(GBD), n (\%)†

\begin{tabular}{|c|c|c|}
\hline $\begin{array}{l}\text { Central Europe, Eastern } \\
\text { Europe and Central Asia }\end{array}$ & $123(30.7)$ & $30(26.5)$ \\
\hline High-income countries & 65 (16.2) & $28(24.8)$ \\
\hline $\begin{array}{l}\text { Latin America and } \\
\text { Caribbean }\end{array}$ & $1(0.2)$ & $1(0.9)$ \\
\hline $\begin{array}{l}\text { North Africa and Middle } \\
\text { East }\end{array}$ & $74(18.5)$ & $20(17.7)$ \\
\hline South Asia & $68(17.0)$ & 18 (15.9) \\
\hline $\begin{array}{l}\text { Southeast Asia, East } \\
\text { Asia and Oceania }\end{array}$ & $15(3.7)$ & $3(2.7)$ \\
\hline Sub-Saharan Africa & $54(13.5)$ & $12(10.6)$ \\
\hline \multicolumn{3}{|l|}{ Partner Norwegian, n (\%) } \\
\hline Yes & $54(13.5)$ & $22(19.5)$ \\
\hline No & $347(86.5)$ & $91(80.5)$ \\
\hline $\begin{array}{l}\text { Length of residency } \\
\text { (months), mean (SD) }\end{array}$ & $35.6(19.4)$ & $38.3(18.1)$ \\
\hline \multicolumn{3}{|l|}{ Education, n (\%) } \\
\hline No completed education & $16(4.0)$ & $6(5.3)$ \\
\hline $\begin{array}{l}\text { Primary/secondary } \\
\text { school }\end{array}$ & $151(37.7)$ & 27 (23.9) \\
\hline University & $234(58.4)$ & $80(70.8)$ \\
\hline \multicolumn{3}{|l|}{ Marital status, n (\%) } \\
\hline Single/divorced & $21(5.2)$ & $5(4.4)$ \\
\hline Cohabitant/married & $380(94.8)$ & 108 (95.6) \\
\hline \multicolumn{3}{|l|}{ Economic status, n (\%) } \\
\hline Very low-low & $19(4.7)$ & $8(7.1)$ \\
\hline Low-moderate & $60(15.0)$ & $21(18.6)$ \\
\hline High & $313(78.1)$ & $82(72.6)$ \\
\hline Unknown & $9(2.2)$ & $2(1.8)$ \\
\hline
\end{tabular}

Table 1 Continued

\section{Socio-demographic and} clinical characteristics

All $(n=401)$

Dissatisfied $^{*}$ ( $n=113)$

Employment status, $\mathrm{n}(\%)$

$\begin{array}{lll}\text { Employed } & 228(56.9) & 69(61.1) \\ \text { Unemployed } & 173(43.1) & 44(38.9)\end{array}$

Reason for migration, $\mathrm{n}$

(\%)

$\begin{array}{lrr}\text { Refugee } & 41(10.2) & 12(10.6) \\ \text { Family reunification } & 183(45.6) & 51(45.1) \\ \text { Work/education } & 177(44.1) & 50(44.2)\end{array}$

Norwegian

comprehension, $\mathrm{n}(\%)$

$\begin{array}{lcc}\text { None } & 69(17.2) & 20(17.7) \\ \text { With difficulties } & 149(37.2) & 39(34.5) \\ \text { Good } & 158(39.4) & 40(35.4) \\ \text { Fluently } & 25(6.2) & 14(12.4)\end{array}$

Clinical characteristics

BMI, mean (SD) $23.2(4.0) \quad 23.3(4.1)$

Number of children, mean $1.6(0.8) \quad 1.6(0.8)$ (SD)

GA first antenatal visit, $\quad 9.5(4.5) \quad 9.5(4.5)$
mean (SD)

Care received by $\ddagger$, $(\%)$

\begin{tabular}{|c|c|c|}
\hline General practitioner & $328(81.8)$ & $94(83.2)$ \\
\hline Midwife & 331 (83.0) & $96(85.7)$ \\
\hline Obstetrician & $114(28.4)$ & $32(28.3)$ \\
\hline \multicolumn{3}{|l|}{ Parity, n (\%) } \\
\hline Primiparous & $229(57.1)$ & $74(65.5)$ \\
\hline Multiparous & $172(42.9)$ & $39(34.5)$ \\
\hline \multicolumn{3}{|l|}{$\begin{array}{l}\text { Evaluation of own health, } \\
\mathrm{n}(\%)\end{array}$} \\
\hline Good & $363(90.5)$ & $104(92.0)$ \\
\hline Neither good nor bad & $33(8.2)$ & $7(6.2)$ \\
\hline Bad & $5(1.2)$ & $2(1.8)$ \\
\hline \multicolumn{3}{|l|}{ Comorbidity, n (\%) } \\
\hline Yes & 79 (19.7) & $17(15.0)$ \\
\hline No & $322(80.3)$ & $96(85.0)$ \\
\hline
\end{tabular}

Pregnancy complication, $\mathrm{n}(\%)$

$\begin{array}{lll}\text { Yes } & 213(53.1) & 69(61.1) \\ \text { No } & 187(46.6) & 44(38.9)\end{array}$

Obstetric interventions,

$\mathrm{n}(\%)$

\begin{tabular}{lrl} 
Induction & $97(24.2)$ & $33(29.2)$ \\
Vacuum & $52(13.0)$ & $18(15.9)$ \\
Caesarean section & $72(18.0)$ & $22(19.5)$ \\
Episiotomy & $91(22.7)$ & $27(23.9)$ \\
Epidural & $242(60.3)$ & $70(61.9)$ \\
\hline
\end{tabular}

Continued 


\begin{tabular}{lcc}
\hline $\begin{array}{l}\text { Table } 1 \text { Continued } \\
\text { Socio-demographic and } \\
\text { clinical characteristics }\end{array}$ & All (n=401) & $\begin{array}{l}\text { Dissatisfied* } \\
\text { (n=113) }\end{array}$ \\
\hline \multicolumn{1}{c}{ Pudendal } & $21(5.2)$ & $9(8.0)$ \\
$\begin{array}{l}\text { Complications during } \\
\text { birth, } \mathrm{n}(\%)\end{array}$ & $19(4.7)$ & $7(22.6)$ \\
$\begin{array}{l}\text { Postpartum } \\
\text { haemorrhage }\end{array}$ & $27(6.7)$ & $8(25.8)$ \\
\hline $\begin{array}{l}\text { Transfer to NICU } \\
\text { Antibiotic treatment }\end{array}$ & $55(13.7)$ & $16(51.6)$ \\
$\begin{array}{l}\text { Planned pregnancy, } \mathrm{n}(\%) \\
\text { Yes }\end{array}$ & $300(74.8)$ & $78(69.0)$ \\
\hline No & $101(25.2)$ & $35(31.0)$ \\
\hline
\end{tabular}

${ }^{*}$ Percentages are column percentages.

†One missing.

$\ddagger$ More than one healthcare provider possible.

.BMI, Body mass index; GA, Gestational age ; GBD, Global Burden

of Disease; NICU, Neonatal intensive care unit.

education (adjusted OR: 0.39 , 95\% CI 0.22 to 0.73 ). Women with a Norwegian language comprehension categorised as 'good' or 'with difficulties', as compared with 'fluently', had decreased odds of being dissatisfied (adjusted OR: 0.26 and $0.24,95 \%$ CI 0.09 to 0.71 and 0.09 to 0.62 , respectively). Not having a planned pregnancy were associated with greater odds of being dissatisfied with care. No significant association was found between satisfaction and migrant-specific variables such as mother's region of birth, reason for migration and length of residency. Overall dissatisfaction with care was most pronounced during pregnancy (23\%) as compared with during birth (12\%). For 'dissatisfaction in pregnancy', all the variables from figure 2 were significantly associated, in addition to being primiparous (online supplemental file 2). When analysing 'dissatisfaction during birth', none of the variables from figure 2 were significant, including birth-related factors: 'complications during birth' and 'caesarean section'.
Negative healthcare experiences and their association with women's dissatisfaction

We found a higher proportion of negative responses for different healthcare experiences as compared with the overall dissatisfaction of care (table 2). One-third of women $(33.4 \%)$ had not understood the information provided by the healthcare personnel during a consultation or while being admitted to hospital. Of these, $85 \%$ said that they would have understood the information better in another language. Among the one-third, there was a higher proportion of less fluency in Norwegian and lower education, compared with the two-thirds who understood the information. More than one-fourth of the women experienced that healthcare personnel did not ask if they had questions and did not spend enough time providing explanations. Half of the women had experienced prolonged waiting time before receiving care. One in every five women had experienced that healthcare personnel made a decision without taking their wishes into account.

Healthcare personnel not taking the women's concerns seriously (OR: $6.8,95 \%$ CI 4.2 to 11.2), not spending enough time providing information (OR: 6.0, 95\% CI 3.8 to 9.7 ) and perceived prolonged waiting time for the migrant women (OR: 5.2, 95\% CI 3.2 to 8.5 ) increased the odds of being overall dissatisfied the most (figure 3 ).

\section{Negative healthcare experiences and their association with reason for migration}

More refugee women felt treated differently by healthcare personnel because of religion, skin colour, language, etc ( $24.4 \%$ vs $9.3 \%, \mathrm{p}=0.022)$ and understood less information $(51.2 \%$ vs $27.2 \%, \mathrm{p}=0.008)$, compared with women who migrated due to family reunification and work/ education, respectively (table 2 ). The majority of refugee women originated from Eritrea $(34.1 \%)$, Syria $(19.5 \%)$, Iraq $(7.3 \%)$ and Somalia (7.3\%). Women who migrated due to family reunification were more dissatisfied with the pain management $(17.5 \%$ vs $7.3 \%, \mathrm{p}=0.01)$ and felt that decisions were made without their wishes being taken into account (24.6\% vs $14.1 \%, \mathrm{p}=0.03)$, compared with women who migrated due to work/education.

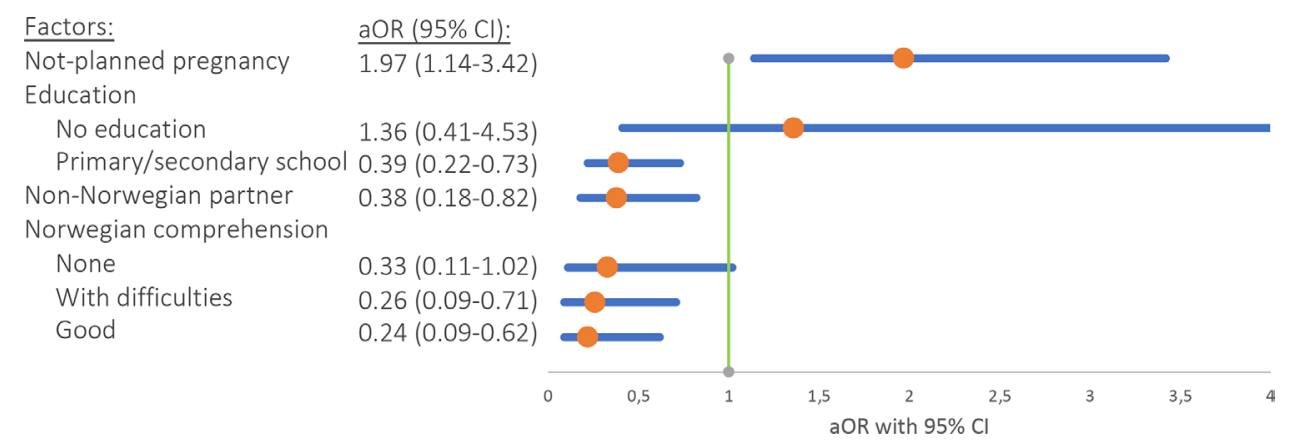

Figure 2 Association between socio-demographic and clinical factors with overall dissatisfaction with care (combined for during pregnancy and birth), with adjusted OR and $95 \% \mathrm{Cl}$. Adjusted for Norwegian partner, education, Norwegian comprehension, parity, planned pregnancy, caesarean section, mother's region of birth, reason for migration, maternal age and length of residency. 
Table 2 Negative healthcare experiences for all participants and for subgroups of migrants with refugee, family reunification and work/education, with frequency, $\mathrm{N}$, and percentage, $\%$

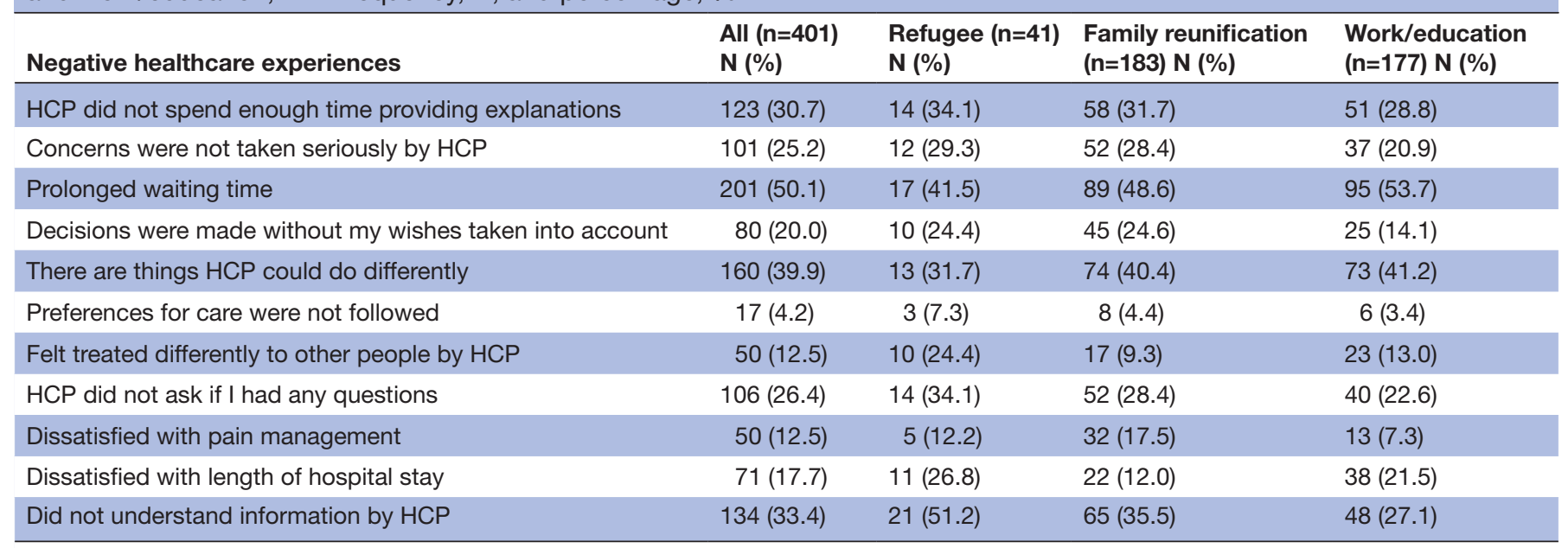

HCP, healthcare personnel.

\section{DISCUSSION}

This study identified factors associated with maternal satisfaction with healthcare for recently arrived migrants. A substantial proportion of participants were satisfied with the received healthcare. However, the degree of dissatisfaction was higher among women with unplanned pregnancy, higher education, good language skills and a Norwegian partner. One-third of all women reported not to understand the information provided by the healthcare personnel during maternity care. In addition, more women with refugee background felt treated differently by the healthcare personnel because of factors such as religion, language and skin colour, than women who migrated due to family reunification.

Measures of satisfaction are important because it is assumed that they reflect quality of care. In consonance with the definition of satisfaction of care, 'high satisfaction' can indicate good care received but also 'low expectations' and vice versa. ${ }^{31}$ This is especially true for the perinatal period where it may be difficult to distinguish between the childbirth experience and the actual care received.$^{32}$ The recently arrived migrant women's varying background can highly affect their expectations, depending on, for example, previous experience with healthcare in other countries, cultural context and knowledge about Norwegian healthcare system. ${ }^{33}$ This is reflected in our results; even though the overall satisfaction was high, consistent with existing literature, ${ }^{34}{ }^{35}$ we found a high rate of negative responses for some healthcare experiences. This emphasises that an overall satisfaction score may not be adequate to measure quality of care. In agreement with our study, a recent review article on maternity care in Nordic countries also found experiences of care-related discrimination among refugees. ${ }^{36}$ This may indicate implicit bias among healthcare personnel. However, this needs to be further explored, especially since negative implicit bias among healthcare personnel has the potential to contribute to disparities in health. ${ }^{37}$

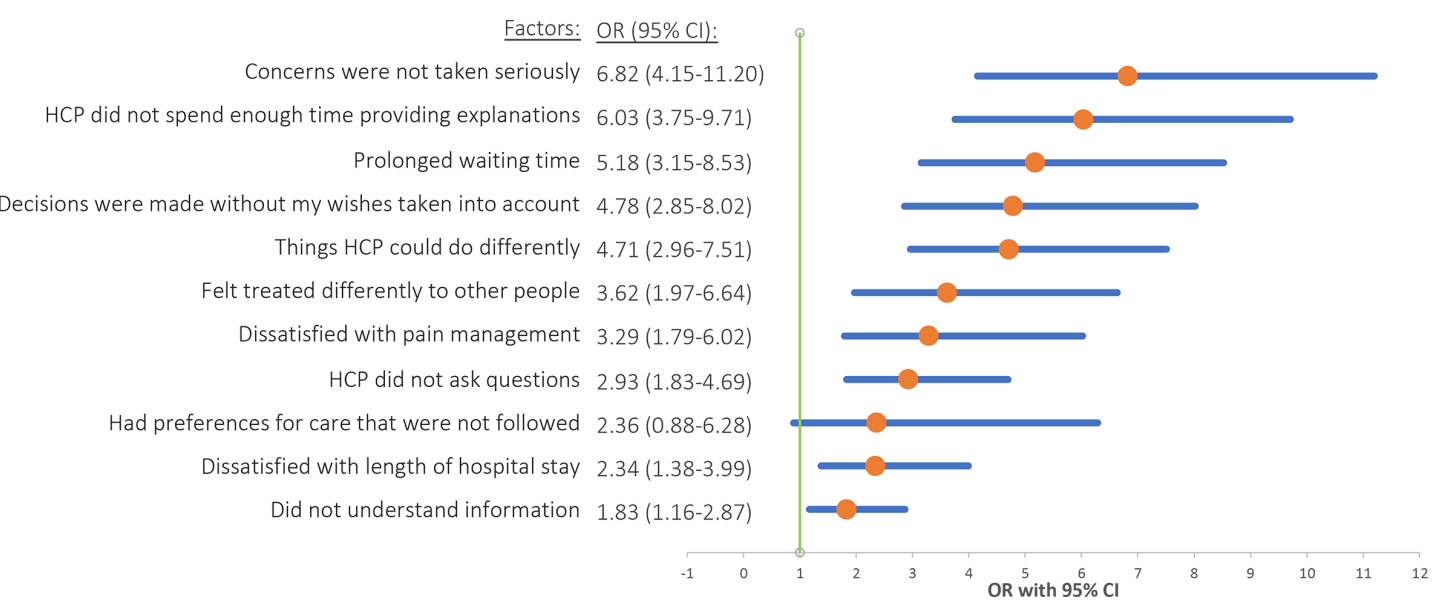

Figure 3 Association between negative healthcare experiences and overall dissatisfaction with care (combined for during pregnancy and birth), with crude OR and $95 \% \mathrm{Cl}$. 
Care during pregnancy was the time period with highest proportion of dissatisfaction in our study. Contrary to this, a Dutch study showed that non-Western migrants were most satisfied with the antenatal care, ${ }^{38}$ while a British study found little difference in satisfaction between the three periods. ${ }^{34}$ These differences might be explained by different ways of organising the maternity care between countries, for instance, a more non-intervening approach to perinatal care, continuity of care and more home births in the Netherlands compared with Norway. Contradicting previous research, we found no difference in women's satisfaction with maternity care given by a general practitioner or a midwife. ${ }^{39}$

In our study, women with high education were less satisfied, compared with those with some education. This difference can be explained by different expectations, which in turn can be influenced by health system literacy. A study specifically measuring expectations with antenatal care among vulnerable women, including migrants, found low expectations among women with a lower level of education. ${ }^{35}$ Contrary to our finding, studies not looking specifically at migrants have suggested the opposite $^{40}$ and no association between education and satisfaction. ${ }^{41}$ Indeed, several studies from developing countries have showed that women who are illiterate or with only primary education were more satisfied compared with those with higher education, ${ }^{42} 43$ in line with our findings.

Communication and language barriers have been pointed out as main obstacles in achieving high-quality care for migrant women, ${ }^{2} 304445$ yet few quantitative studies have included language proficiency as a determinant for satisfaction. We did, indeed, find that a high proportion of women had not understood the information delivered by healthcare personnel and the majority of them believed they would have better understanding in a different language. This language barrier is a worrying finding in terms of quality of care. In agreement with our finding, a recent study indicated 'effective communication' to be one of the strongest associated factors with overall satisfaction. ${ }^{46}$ Hence, increased satisfaction among women with less fluency in Norwegian language as shown in our study can be due to lower expectations. Gürbüz et al who also used the questionnaire tool MFMCQ surprisingly found no association between language proficiency and satisfaction. ${ }^{47}$ In order to ensure high quality of care, there is a need for migrant-friendly communication, which includes access to professional interpreter services, provision of written materials for migrants in their language and training of healthcare personnel in intercultural communication.

Having a Norwegian partner increased the odds of being dissatisfied in our study. A recent study from Norway found increased odds for adverse outcomes for babies with two migrant parents compared with one and linked it to disadvantages such as communication problems and levels of health system literacy. ${ }^{23}$ Our findings may, therefore, reflect expectations rather than actual quality of care. We found no association between overall satisfaction and mother's region of birth in our study, in agreement with other studies, ${ }^{1948} 49$ including one conducted in
Norway. ${ }^{50}$ While some studies have found higher satisfaction among migrants compared with non-migrants, ${ }^{35} 4142$ other studies have found the opposite. ${ }^{40}$ However, we did not include non-migrants, as our aim was not to compare migrant women to the majority population.

\section{Strength and limitations}

A strength of this study was the use of face-to-face interviews with interpreter when needed, enabling all women to participate, not limited by language or literacy. In this way, we were also able to reduce the chance of missing data and limiting misinterpretation of questions. The use of the questionnaire tool MFMCQ enables comparability across countries. The clinical characteristics of study participants were comparable with national statistics on obstetric interventions and complications during birth. ${ }^{51}$ As this is a cross-sectional study, true cause-andeffect relationship cannot be assessed. The questionnaire was administered within some days after birth not only to ensure responses from hard-to-reach groups but also potentially introducing bias. Immediately after birth, women tend to show high satisfaction levels, the so-called 'halo effect', where the women are filled with relief for having a healthy baby. ${ }^{52}$ Social desirability bias could also affect the answers, since the interviews were conducted by healthcare personnel in the postnatal ward. However, the interviewing healthcare personnel did not provide care to the participating women and there is no consensus as to the right time for a survey ${ }^{19}$ The lack of measurement of expectations may have limited our understanding of some of the variables such as education and parity. ${ }^{53}$

\section{Practical implications of the study and recommendations for future research}

The findings of this study provide usable information for the improvement of maternal care to become 'migrant friendly'. Healthcare personnel assessing the pregnant women's literacy, expectations and pregnancy intention would assist in better identifying the women in need for additional support services to ensure higher satisfaction with care and better use of healthcare services. To ensure optimal communication, tools such as provision of professional interpreter, support material in various languages and intercultural mediation are required. This study emphasises that in migrant population, specific healthcare experiences rather than overall satisfaction may be important to evaluate quality of care. Including more women from certain vulnerable subgroups such as refugees and undocumented migrants in future studies would assist in deeper and more fully understanding of factors associated with dissatisfaction. Additionally, it would be important to understand the relationship between being dissatisfied and the use of healthcare services as well as between dissatisfaction and maternity outcomes. Including the partner's perception of care and predictors for satisfaction would further assist in understanding pathways to achieve higher quality of care.

Author affiliations

${ }^{1}$ Norwegian Research Centre for Women's Health, Department of Obstetrics and Gynecology, Oslo University Hospital, Oslo, Norway 
${ }^{2}$ Department of Community Medicine and Global Health, Institute of Health and Society, Faculty of Medicine, University of 0slo, Oslo, Norway

${ }^{3}$ Department of International Studies and Interpreting, Section for Diversity Studies, Oslo Metropolitan University, Oslo, Norway

${ }^{4}$ Institute of Clinical Medicine, Faculty of Medicine, University of Oslo, Oslo, Norway ${ }^{5}$ Centre for Biostatistics and Epidemiology, Oslo University Hospital, Oslo, Norway ${ }^{6}$ Division of Mental and Physical Health, Norwegian Institute of Public Health, Oslo, Norway

Acknowledgements We thank all the participating women and health staff at Oslo University Hospital and Akershus University Hospital that enabled us to perform this study. We thank midwives Zusan Ibrahim, Kerstin Adolfsson and Maria Stivang for their help in data collection and Hanna Ottesen for useful comments on the manuscript.

Contributors SB modified the questionnaire, collected survey data, conducted the analysis, interpreted results and wrote the first draft of the manuscript. JS developed the idea for the study, secured the funding, contributed to results interpretation and contributed to manuscript revisions. BVL and SV developed the idea for the study, secured the funding, helped interpreted results and contributed to manuscript revisions. LMD contributed to data and statistical analysis and manuscript revision. KMO helped interpreted results and contributed to manuscript revisions. IS developed the idea for the study, secured the funding, interpreted results and revised manuscript. All authors approved the final version of the manuscript.

Funding This work was supported by research council of Norway (grant number: 273328).

\section{Competing interests None declared.}

Patient consent for publication A written consent was obtained from those who volunteered to participate in the study.

Ethics approval This study was approved by 0slo University Hospital's ethical review committee (approval number: 18/15786) and Akershus University Hospital's ethical review committee (approval number: 18/05310). The overall MiPreg study was approved by regional committees for medical and health research ethics (approval number: 2018/1086).

Provenance and peer review Not commissioned; externally peer reviewed.

Data availability statement Data are available upon reasonable request. The data that support the findings of this study are available from the corresponding author, $\mathrm{SB}$, upon reasonable request. The data are not publicly available due to their containing information that could compromise the privacy of research participants.

Supplemental material This content has been supplied by the author(s). It has not been vetted by BMJ Publishing Group Limited (BMJ) and may not have been peer-reviewed. Any opinions or recommendations discussed are solely those of the author(s) and are not endorsed by BMJ. BMJ disclaims all liability and responsibility arising from any reliance placed on the content. Where the content includes any translated material, BMJ does not warrant the accuracy and reliability of the translations (including but not limited to local regulations, clinical guidelines, terminology, drug names and drug dosages), and is not responsible for any error and/or omissions arising from translation and adaptation or otherwise.

Open access This is an open access article distributed in accordance with the Creative Commons Attribution Non Commercial (CC BY-NC 4.0) license, which permits others to distribute, remix, adapt, build upon this work non-commercially, and license their derivative works on different terms, provided the original work is properly cited, appropriate credit is given, any changes made indicated, and the use is non-commercial. See: http://creativecommons.org/licenses/by-nc/4.0/.

ORCID iD

Sukhjeet Bains http://orcid.org/0000-0001-8720-4732

\section{REFERENCES}

1 Jakab DZ. Statement - the challenges of migration require migrant-sensitive health systems for today and for the future who regional office for Europe: who regional office for Europe, 2015. Available: https://www.euro.who.int/en/about-us/regional-director/ regional-directors-emeritus/dr-zsuzsanna-jakab,-2010-2019/ speeches-and-presentations-by-year/2015/statement-thechallenges-of-migration-require-migrant-sensitive-health-systemsfor-today-and-for-the-future accessed 071020202020
2 Almeida LM, Caldas J, Ayres-de-Campos D, et al. Maternal healthcare in migrants: a systematic review. Matern Child Health $J$ 2013;17:1346-54.

3 Dias S, Gama A, Cortes M, et al. Healthcare-seeking patterns among immigrants in Portugal. Health Soc Care Community 2011;19:514-21.

4 Gissler M, Alexander S, MacFarlane A, et al. Stillbirths and infant deaths among migrants in industrialized countries. Acta Obstet Gynecol Scand 2009;88:134-48.

5 Draper ES, Gallimore ID, Smith LK, Kurinczuk JJ, Smith PW, Boby T, Fenton AC, Manktelow BN, on behalf of the MBRRACE-UK Collaboration. MBRRACE-UK perinatal mortality surveillance report, UK perinatal deaths for births from January to December 2017. Leicester The Infant Mortality and Morbidity Studies, Department of Health Sciences, University of Leicester; 2019.

6 Alderliesten ME, Vrijkotte TGM, van der Wal MF, et al. Late start of antenatal care among ethnic minorities in a large cohort of pregnant women. BJOG 2007;114:1232-9.

7 Kupek E, Petrou S, Vause S, et al. Clinical, provider and sociodemographic predictors of late initiation of antenatal care in England and Wales. BJOG 2002;109:265-73.

8 Cresswell JA, Yu G, Hatherall B, et al. Predictors of the timing of initiation of antenatal care in an ethnically diverse urban cohort in the UK. BMC Pregnancy Childbirth 2013;13:103.

9 Bains S, Mæland KS, Vik ES. Prenatal health of immigrant women in Norway - an exploratory literature review. Tidsskr Nor Laegeforen 2021;141. doi:10.4045/tidsskr.20.0428. [Epub ahead of print: https:// pubmed.ncbi.nlm.nih.gov/33528142/

10 Heaman M, Bayrampour H, Kingston D, et al. Migrant women's utilization of prenatal care: a systematic review. Matern Child Health J 2013:17:816-36.

11 Fitzpatrick R. Surveys of patient satisfaction: II--Designing a questionnaire and conducting a survey. BMJ 1991;302:1129-32.

12 Kincey J, Bradshaw P, Ley P. Patients' satisfaction and reported acceptance of advice in general practice. J $R$ Coll Gen Pract 1975;25:558-66.

13 Cleary PD, McNeil BJ. Patient satisfaction as an indicator of quality care. Inquiry 1988;25:25-36.

14 Guldvog B. Can patient satisfaction improve health among patients with angina pectoris? Int J Qual Health Care 1999;11:233-40.

15 World Health Organization. Standards for improving quality of maternal and newborn care in health facilities, 2016. Available: https://www.who.int/maternal_child_adolescent/documents/ improving-maternal-newborn-care-quality/en/ [Accessed 02 Oct 2020].

16 Sitzia J, Wood N. Patient satisfaction: a review of issues and concepts. Soc Sci Med 1997;45:1829-43.

17 Wilde-Larsson B, Sandin-Bojö A-K, Starrin B, et al. Birthgiving women's feelings and perceptions of quality of intrapartal care: a nationwide Swedish cross-sectional study. J Clin Nurs 2011;20:1168-77.

18 Henriksen L, Grimsrud E, Schei B, et al. Factors related to a negative birth experience - A mixed methods study. Midwifery 2017;51:33-9.

19 Hodnett ED. Pain and women's satisfaction with the experience of childbirth: a systematic review. Am J Obstet Gynecol 2002;186:S160-72.

20 Srivastava A, Avan BI, Rajbangshi P, et al. Determinants of women's satisfaction with maternal health care: a review of literature from developing countries. BMC Pregnancy Childbirth 2015;15:97.

21 van den Akker T, van Roosmalen J. Maternal mortality and severe morbidity in a migration perspective. Best Pract Res Clin Obstet Gynaecol 2016;32:26-38.

22 Gagnon AJ, Redden KL. Reproductive health research of women migrants to Western countries: a systematic review for refining the clinical lens. Best Pract Res Clin Obstet Gynaecol 2016;32:3-14.

23 Vik ES, Aasheim V, Schytt E, et al. Stillbirth in relation to maternal country of birth and other migration related factors: a populationbased study in Norway. BMC Pregnancy Childbirth 2019;19:5.

24 Saastad E, Vangen S, Frøen JF. Suboptimal care in stillbirths - a retrospective audit study. Acta Obstet Gynecol Scand 2007;86:444-50.

25 The Norwegian Directorate of Health. Healthcare for persons without legal residence in Norway, 2020. Available: https://www.helsenorge. no/en/foreigners-in-norway/healthcare-for-persons-without-legalresidence/ [Accessed 19 Oct 2020].

26 The Norwegian Directorate of Health. Check-Ups during pregnancy, 2020. Available: https://www.helsenorge.no/en/pregnancy-andmaternity-care-in-norway/check-ups-during-pregnancy/ [Accessed 19 Oct 2020].

27 The Norwegian Directorate of Health. Follow-Up care during the post-natal period, 2020. Available: https://www.helsenorge.no/en/ 
etter-fodsel/follow-up-care-during-the-post-natal-period/ [Accessed 19 Oct 2020].

28 Gagnon AJ, DeBruyn R, Essén B, et al. Development of the migrant friendly maternity care questionnaire (MFMCQ) for migrants to Western societies: an international Delphi consensus process. BMC Pregnancy Childbirth 2014;14:200.

29 The Institute for Health Metrics and Evaluation. What countries are in each region? 2020. Available: http://www.healthdata.org/gbd/faq [Accessed 19 Oct 2020].

30 Brown S, Lumley J. Changing childbirth: lessons from an Australian survey of 1336 women. Br J Obstet Gynaecol 1998;105:143-55.

31 Sofaer S, Firminger K. Patient perceptions of the quality of health services. Annu Rev Public Health 2005;26:513-59.

32 Rudman A, El-Khouri B, Waldenström U. Women's satisfaction with intrapartum care - a pattern approach. J Adv Nurs 2007;59:474-87.

$33 \mathrm{Ng} \mathrm{C}$, Newbold KB. Health care providers' perspectives on the provision of prenatal care to immigrants. Cult Health Sex 2011:13:561-74.

34 van Teijlingen ER, Hundley V, Rennie A-M, et al. Maternity satisfaction studies and their limitations: "What is, must still be best". Birth 2003;30:75-82.

35 Galle A, Van Parys A-S, Roelens K, et al. Expectations and satisfaction with antenatal care among pregnant women with a focus on vulnerable groups: a descriptive study in Ghent. BMC Womens Health 2015;15:112.

36 Leppälä S, Lamminpää R, Gissler M, et al. Humanitarian migrant women's experiences of maternity care in Nordic countries: a systematic integrative review of qualitative research. Midwifery 2020;80:102572.

37 FitzGerald C, Hurst S. Implicit bias in healthcare professionals: a systematic review. BMC Med Ethics 2017;18:19.

38 Peters IA, Posthumus AG, Steegers EAP, et al. Satisfaction with obstetric care in a population of low-educated native Dutch and non-Western minority women. focus group research. PLoS One 2019:14:e0210506.

39 Harvey S, Rach D, Stainton MC, et al. Evaluation of satisfaction with midwifery care. Midwifery 2002;18:260-7.

40 Tocchioni V, Seghieri C, De Santis G, et al. Socio-Demographic determinants of women's satisfaction with prenatal and delivery care services in Italy. Int J Qual Health Care 2018;30:594-601.
41 Fumagalli S, Colciago E, Antolini L, et al. Variables related to maternal satisfaction with intrapartum care in northern Italy. Women Birth 2021;34:154-61.

42 Kebede DB, Belachew YB, Selbana DW, et al. Maternal satisfaction with antenatal care and associated factors among pregnant women in Hossana town. Int J Reprod Med 2020;2020:1-8.

43 Onyeajam DJ, Xirasagar S, Khan MM, et al. Antenatal care satisfaction in a developing country: a cross-sectional study from Nigeria. BMC Public Health 2018;18:368.

44 Santiago MdaCF, Figueiredo MH. Immigrant women's perspective on prenatal and postpartum care: systematic review. J Immigr Minor Health 2015;17:276-84.

45 Small R, Roth C, Raval M, et al. Immigrant and non-immigrant women's experiences of maternity care: a systematic and comparative review of studies in five countries. BMC Pregnancy Childbirth 2014;14:152.

46 Lazzerini M, Mariani I, Semenzato C, et al. Association between maternal satisfaction and other indicators of quality of care at childbirth: a cross-sectional study based on the who standards. BMJ Open 2020;10:e037063.

47 Gürbüz B, Großkreutz C, Vortel M, et al. The influence of migration on women's satisfaction during pregnancy and birth: results of a comparative prospective study with the migrant friendly maternity care questionnaire (MFMCQ). Arch Gynecol Obstet 2019;300:555-67.

48 Sadler LC, Davison T, McCowan LM. Maternal satisfaction with active management of labor: a randomized controlled trial. Birth 2001;28:225-35

49 Conesa Ferrer MB, Canteras Jordana M, Ballesteros Meseguer C, et al. Comparative study analysing women's childbirth satisfaction and obstetric outcomes across two different models of maternity care. BMJ Open 2016;6:e011362.

50 Sjetne IS, Iversen HH, pregnancy Dexperienceswith. Do experiences with pregnancy, birth and postnatal care in Norway vary by the women's geographic origin? A comparison of cross-sectional survey results. BMC Pregnancy Childbirth 2017;17:37

51 Medical Birth Registry of Norway. Norwegian Institute of public health, 2020. Available: http://statistikkbank.fhi.no/mfr/ accessed 26.09.2020

52 Britton JR. The assessment of satisfaction with care in the perinatal period. J Psychosom Obstet Gynaecol 2012;33:37-44.

53 Linder-Pelz S. Social psychological determinants of patient satisfaction: a test of five hypothesis. Soc Sci Med 1982;16:583-9. 